\title{
The influence of obesity in patients with prostate cancer - Review of the literature
}

\author{
Maximilien C. Goris Gbenou \\ Valence Hospital, Department of Urology, Valence, France \\ Corresponding author: Dr Maximilien C. Goris Gbenou, Valence Hospital, Department of \\ Urology, 179, Boulevard Maréchal Juin, 2600 Valence, France \\ Submission date: November 4, 2012; Acceptance date: April 26, 2013; Publication date: April \\ 29,2013
}

\section{ABSTRACT:}

Recent studies have demonstrated an association between higher body mass index and increased aggressiveness in prostate cancer.

The present narrative review, based on a search of Medline ${ }^{\circledR}$ and Embase ${ }^{\circledR}$ databases from October 1982 to October 2012, explores the relationship between higher body mass index and localized prostate cancer. In particular, the current epidemiological and mechanistic evidence for interactions between obesity and prostate cancer are discussed.

Obesity is associated with alterations in androgen levels, decreased sex hormone binding globulin and increased estrogen levels, insulin resistance, hyperglycemia, alterations in plasma lipoprotein levels particularly raised triglycerides and reduced high density lipoprotein, decreased levels of adiponectin, and increased levels of circulating insulin-growth factor- 1, leptin and dietary saturated fats. Obese men have more aggressive prostate cancer with a greater percentage prostate involvement, increased tumor volume and higher-grade disease, enlarged prostates, high prostate-specific antigen levels, increased risk of having positive margins and recurrence.

Moreover, there is strong evidence of the beneficial effects of functional foods for the treatment of obesity. Additionally, an increasing number of studies support that obesity-induced inflammation plays an important role in the development of obesity-related pathologies. Despite, the beneficial role of nutriment in prostate cancer control, the use of functional foods in prostate cancer is not recommended for lack of large epidemiological studies.

This data supports the hypothesis that obese men have more aggressive prostate cancers and that the obesity is a modifiable risk factor of prostate cancer.

Key Words: prostate cancer, metabolic syndrome, obesity, high BMI, risk factor, diet, functional foods.

\section{INTRODUCTION:}


Prostate cancer is now recognized as a major public health issue affecting western countries. It remains the most common malignancy and the second-leading cause of cancer deaths among men in the USA, with an estimated 218,890 new cases and 27,050 deaths in 2007 in the USA [1]. In Europe, with an incidence rate of 214 cases per 1000 men, prostate cancer is the most common solid neoplasm, exceeding lung and colorectal cancer [2]. Additionally, since 1985, there has been a slight increase in most countries in the number of deaths from prostate cancer, even in countries or regions where prostate cancer is uncommon [3].

Rates of obesity, a condition defined as having "excessive body fat", have risen alarmingly over the last decade with approximately one in three adults in the United States being considered obese as compared to one in six 20 years ago[4]. Excess body weight is associated with increased risk of cancer at several organ sites, including colon, breast, endometrium, esophagus and prostate. From a biological perspective, one can put forth a number of potential mechanisms by which obesity might promote prostate cancer and/or prostate cancer progression, including: reduced levels of testosterone, increased levels of estrogen, co-existence of diabetes or metabolic syndrome, increased levels of circulating insulin-growth factor-one (IGF-1), increased levels of leptin, decreased levels of adiponectin and increased dietary saturated fats [5].

The increase in the incidence of prostate cancer is related to prostate-specific antigen (PSA)based screening [6]. That the identification of risk factors for aggressive prostate cancer allows better treatment options for patients is now well established [7]. Obesity currently represents one of these risk factors. In fact, increasing recent evidence is tending towards an association between obesity and more aggressive prostate cancer, increased risk of high-grade prostate cancer and prostate cancer mortality but also possibly a reduced risk of low-grade prostate cancer [8]. Obese men have a greater risk of adverse pathological features and biochemical recurrence after radical prostatectomy. The higher BMI was found to be associated with a greater percentage of prostate involvement [9], increased tumor volume, higher-grade disease [9, 10] and enlarged prostates $[11,12]$. Additionally, obese men undergoing radical prostatectomy were shown to have an increased risk of positive margins [13], higher initial PSA with increased risk of recurrence [14], increased risk of upgrading prostate cancer [15] and higher risk of advanced prostate cancer [16]. Metabolic disorders such as diabetes and obesity, as well as metabolic syndrome have been shown in population-based and experimental studies to modulate prostate cancer risk and aggressiveness.

OBJECTIVE: The purpose of the present review was to assess the impact of obesity on prostate cancer in men. In this review the current epidemiological and mechanistic evidence regarding the interactions between obesity and prostate cancer will be discussed.

\section{METHODS:}

Published literature on the relationship between obesity and prostate cancer was obtained using a Pubmed® search limited to English language studies and critically reviewed. The following keywords were used: prostate cancer, obesity, high BMI, recurrence and survival, biological alterations.

\section{RESULTS AND DISCUSSION:}


Definition and physiopathology of obesity: According to the World Health Organization (WHO) and the National Institutes of Health (NIH), overweight is defined as a body mass index (BMI) over $25 \mathrm{~kg} / \mathrm{m} 2$ and obesity as over $30 \mathrm{~kg} / \mathrm{m} 2$. BMI is easy to use but other definitions have been proposed in the literature including waist-to-hip ratio (WHR), body fat percentage, skin fold thickness, crude weight, and lean body mass [17].

A disproportionate amount of body fat within the abdominal cavity, otherwise known as visceral obesity, best predicts the negative health outcomes associated with high levels of body fat. Abdominal fat distribution is associated with several metabolic and hormonal derangements including decreased levels of sex hormone binding globulin (SHBG), decreased levels of testosterone, increased levels of estrogen, insulin resistance, hyperglycemia, and alterations in levels of plasma lipoprotein particularly increased triglyceride and decreased HDL. Abdominal obesity is associated with an increased risk of heart disease and diabetes and recent studies have also looked into its relationship with prostate health [18].

Recent data support the hypothesis that the hormonal environment in overweight and obese men may alter androgen-dependent prostate growth. Body mass index (BMI) has been implicated in prostate cancer pathology [19].

Biological alterations associated with obesity and involved in prostate pathology:_Recent studies have shown that obesity is associated by multiple biological alterations that are potentially involved in the aggressiveness of prostate cancer (Table 1). Of these anomalies, we can mention [5]: alterations in androgen levels, decreased levels of SHBG, increased levels of estrogen, insulin resistance, hyperglycemia (co-existing diabetes or metabolic syndrome), alterations in levels of plasma lipoprotein particularly increased triglyceride and decreased HDL, decreased levels of adiponectin, and increased levels of circulating IGF-1, leptin and dietary saturated fats [5].

Androgens, SHBG and obesity: According to several epidemiological studies, high BMI is associated with decreased serum testosterone. However, the mechanisms of obesity-associated hypogonadism are complex. Epidemiological studies support a bidirectional relationship between serum testosterone and both obesity and metabolic syndrome [20]. In fact, hypogonadism predicts central obesity and intra-abdominal fat accumulation [21]. Additionally, lowering serum testosterone levels with androgen deprivation therapy in older men with prostate cancer increases body fat mass [22].

In obese men, levels of total testosterone, bioavailable testosterone, diurnal luteinizing hormone and SHBG are reduced [23]. In addition high BMI, central adiposity and metabolic syndrome are associated with and predict low serum total and to a lesser extent free testosterone and SHBG levels [24]. The obese men have what is called relative hypogonadism that increases the aggressiveness of prostate cancer [25]. Androgens are involved in prostate growth and malignant transformation [19] though the exact mechanisms of action are poorly understood and are the subject of some controversy. Metabolic factors and androgens may promote prostate carcinogenesis via multiple mechanisms including inflammation, adipokine action, fatty acid metabolism and IGF signaling. 
The low total testosterone or SHBG levels are also associated with type 2 diabetes, which is another risk factor of prostate cancer [26]. Also, low SHBG was found to be a strong independent predictor of type II diabetes [27].

Estrogen and obesity: Obese men have been shown to have increased levels of estrogen [28]. Animal model-based studies have suggested that the estrogens may originate from aromatized androgens and act with estrogen metabolites to cause prostate cancer [25]. While the androgenreceptor mediated activity of androgens and estrogen receptor-mediated effects of estrogen metabolites are likely necessary, estrogen genotoxicity appears to be a probable critical factor [5, 29].

Table 1: Biological abnormalities observed in obese men may be involved in the mechanism of prostate cancer.

\begin{tabular}{|l|l|l|l|}
\hline Authors, year[ref.] & Study design & $\mathbf{n}$ & Principal findings \\
\hline Brand et al., 2011[21] & $\begin{array}{l}\text { Meta-analysis of } \\
\text { observational } \\
\text { studies }\end{array}$ & 22043 & $\begin{array}{l}\text { The presence of a sex-dependent association } \\
\text { between testosterone and metabolic syndrome: } \\
\text { total testosterone and free-testosterone levels are } \\
\text { lower in men with metabolic syndrome, whereas } \\
\text { they are higher in women with metabolic } \\
\text { syndrome. There are no indications for a sex- } \\
\text { specific association between SHBG and metabolic } \\
\text { syndrome. In both men and women, metabolic } \\
\text { syndrome is associated with lower SHBG levels. }\end{array}$ \\
\hline $\begin{array}{l}\text { Dandona et al, 1998 } \\
{[31]}\end{array}$ & Prospective study & 38 & $\begin{array}{l}\text { Increased cytokines: TNF-a and IL-6, both } \\
\text { are inflammatory cytokines, released by adipose } \\
\text { tissue stimulated by inflammatory stimuli. Serum } \\
\text { concentration of IL-6 and TNF-a are increased in } \\
\text { high BMI and weight loss results in decreased } \\
\text { levels }\end{array}$ \\
\hline Vikan et al., 2010, [28] & $\begin{array}{l}\text { Population-based } \\
\text { prospective cohort } \\
\text { study }\end{array}$ & 1454 & $\begin{array}{l}\text { Men with higher estradiol levels had an } \\
\text { increased risk of later diabetes independent of } \\
\text { obesity, while men with lower total testosterone } \\
\text { and SHBG had an increased risk of diabetes that } \\
\text { appeared to be dependent on obesity.Low } \\
\text { testosterone and SHBG levels and high estradiol } \\
\text { levels are independent predictors of type 2 diabetes } \\
\text { in men. }\end{array}$ \\
\hline
\end{tabular}

Cytokines and obesity: The pro-inflammatory cytokines, IL-6 and TNF-a, released by adipose tissue in response to inflammatory stimuli, and resistin are all adipokines that antagonize the action of insulin [30]. Serum concentrations of IL-6 and TNF-a are increased in high BMI and decreased following weight loss [31]. Additionally, the high levels of IL-6, TNF-alpha and resistin associated with obesity provoke insulin resistance. Such insulin resistance is associated with high risk of prostate cancer via both the obesity-sex hormone pathway [32] and non-insulin related pathway [33]. Insulin antagonizing adipokines are associated with prostate cancer aggressiveness. The levels of IL- 6 are increased in obese prostate cancer patients and may have a possible role in its progression [34]. Levels of circulating adiponectin, an adipocyte secreted 
protein, are not only lower in obesity but are also negatively associated with histological grade and stage of disease in prostate cancer [14].

Obesity and prostate cancer: The higher BMI of obese patients with prostate cancer is associated with a greater percentage of the prostate involvement, increased tumor volume, higher-grade disease and enlarged prostates. Additionally, obese men undergoing radical prostatectomy have an increased risk of positive margins, recurrence, high initial PSA, upgrading prostate cancer and advanced prostate cancer (Table 2).

Several epidemiological studies suggest greater body adiposity may be a modifiable risk factor for high-grade (Gleason 7, Gleason 8-10) prostate cancer and prostate cancer mortality.

Obesity and PSA: Studies on the impact of high BMI on PSA levels are controversial. Indeed, increased BMI, high insulin and type II diabetes mellitus were found associated with increased prostate volume but, paradoxically, with lower PSA levels [35]. Grubb et al. suggested that the inverse relationship between obesity and PSA, in spite of a larger prostate volume, could be the result of hemodilution in larger plasma volumes among obese men [36]. Recently, Mitchell et al. [37] reported that the BMI does not affect the association between the PSA level and tumor volume.

Conflicting results were found in a retrospective study carried out by our group on 464 patients with localized prostate cancer who had undergone radical prostatectomy [38]. We reviewed preoperative BMI and whole prostate weight and used multivariable regression modeling adjusting for age, year of surgery, preoperative serum PSA, pathological stage and Gleason grade. In multivariable regression, preoperative BMI was positively associated with increasing prostate weight $(\mathrm{p}=0.000000)$ and higher initial PSA $(\mathrm{p}=0.00000)$.

Obesity and radical prostatectomy for cancer: Mitchell et al. studied a population of 14,293 patients and found that at the time of prostatectomy for prostate cancer, obese patients have worse pathological features.

Using the clinicopathologic variables, they examined the relationship among the BMI, preoperative PSA level, and tumor volume at radical prostatectomy using multiple linear regression analysis. Elevated BMI was associated with an increased pathologic Gleason score (P $<.0001)$, increased tumor volume $(\mathrm{P}<.0001)$, and increased prostate size $(\mathrm{P}<.0001)$ and additionally, the preoperative PSA level correlated significantly with the tumor volume $(\mathrm{P}<$ .0001) [37].

Concordantly, our study cited above [38] on obese men undergoing radical prostatectomy found a higher biopsy Gleason score $(\mathrm{p}=0.019833)$, higher final Gleason score $(\mathrm{p}=0.00000)$ with increased risk of upgrading prostate cancer (0.00000). Findings of previous studies have found that obesity is related to an increased risk of high-grade prostate cancer and prostate cancer mortality but also possibly to a reduced risk of low-grade prostate cancer [8]. Amling et al [39] and Freedland et al [14] reported obesity (BMI greater than $30 \mathrm{mg} / \mathrm{kg} 2$ and $35 \mathrm{mg} / \mathrm{kg} 2$, respectively) as being associated with higher grade tumors and higher rates of disease recurrence after treatment with radical prostatectomy, and Rodriguez et al [39] found a statistically significant relationship with high grade prostate cancer in a United States cohort. 
Capitanio et al. [40] analyzed the results of 1,275 patients with prostate cancer who underwent radical prostatectomy at a single tertiary care institution, and found that obese men had a high tumor volume which correlated with BMI on univariable analysis $(\mathrm{P}<0.001)$. On multivariable analysis, the BMI reached the independent predictor status after adjustment for age, PSA value, biopsy Gleason score, clinical stage and prostate volume $(\mathrm{P}=0.03)$.

Table 2: Recent clinical studies evaluated the relationship between obesity and prostate cancer.

\begin{tabular}{|c|c|c|c|}
\hline Authors, year [ref.] & Study design & $\mathbf{n}$ & Principal findings \\
\hline $\begin{array}{l}\text { Capitanio et al., } \\
2012 \text { [40] }\end{array}$ & $\begin{array}{l}\text { Retrospective } \\
\text { single-center } \\
\text { study }\end{array}$ & 1275 & $\begin{array}{l}\text { Obese men have high tumor volume and, on univariable } \\
\text { analysis, BMI was correlated with tumor volume at } \\
\text { radical prostatectomy. On multivariable analysis, BMI } \\
\text { reached the independent predictor status after adjustment } \\
\text { for age, prostate-specific antigen value, biopsy Gleason } \\
\text { score, clinical stage and prostate volume. }\end{array}$ \\
\hline $\begin{array}{l}\text { De Nunzio et al., } \\
\text { 2011[49] }\end{array}$ & $\begin{array}{l}\text { Prospective } \\
\text { single-center } \\
\text { study }\end{array}$ & 885 & $\begin{array}{l}\text { Obesity is associated with an increased risk of a high- } \\
\text { grade Gleason score when prostate cancer is diagnosed at } \\
\text { biopsy. }\end{array}$ \\
\hline $\begin{array}{l}\text { Freedland et al., } \\
2004 \text { [14] }\end{array}$ & $\begin{array}{l}\text { Retrospective } \\
\text { single-center } \\
\text { study }\end{array}$ & 1106 & $\begin{array}{l}\text { Obesity is associated with higher-grade tumors, a trend } \\
\text { toward increased risk of positive surgical margins, and } \\
\text { higher biochemical failure rates among men treated with } \\
\mathrm{RP} \text {. A BMI }>\text { or }=35 \mathrm{~kg} / \mathrm{m}(2) \text { was associated with a } \\
\text { higher risk of failure than a BMI between } 30 \text { and } 35 \\
\mathrm{~kg} / \mathrm{m}(2) \text {. }\end{array}$ \\
\hline $\begin{array}{l}\text { Goris Gbenou et al., } \\
2012[38]\end{array}$ & $\begin{array}{l}\text { Retrospective } \\
\text { single-center } \\
\text { study }\end{array}$ & 464 & $\begin{array}{l}\text { Obesity is associated with high prostate weight, } \\
\text { increasing risk of upgrading prostate cancer and higher } \\
\text { initial PSA }\end{array}$ \\
\hline $\begin{array}{l}\text { Kopp et al., } \\
\text { 2011[11] }\end{array}$ & $\begin{array}{l}\text { Retrospective } \\
\text { single-center } \\
\text { study }\end{array}$ & 16325 & $\begin{array}{l}\text { Preoperative BMI is associated with increased prostate } \\
\text { weight. Compared with men with BMI }<25 \mathrm{~kg} / \mathrm{m}(2 \text { ), } \\
\text { men with a BMI } \geq 35 \mathrm{~kg} / \mathrm{m}(2) \text { had a } 40 \% \text { (odds ratio } \\
1.40,95 \% \text { CI } 1.01-1.95 \text { ) increased risk of prostate weight } \\
\text { of at least } 40 \mathrm{~g} \text { and a } 70 \% \text { (odds ratio } 1.70,95 \% \text { CI } 1.32- \\
2.20 \text { ) increased risk of prostate weight of at least } 50 \mathrm{~g} \text {. }\end{array}$ \\
\hline $\begin{array}{l}\text { Mitchell et al., } 2011 \\
\text { [37] }\end{array}$ & $\begin{array}{l}\text { Retrospective } \\
\text { single-center } \\
\text { study }\end{array}$ & 14293 & $\begin{array}{l}\text { Obesity is associated with increased pathologic Gleason } \\
\text { score, increased tumor volume and increased prostate } \\
\text { size. The preoperative PSA level correlated significantly } \\
\text { with the tumor volume. } \\
\text { No significant correlation was found between the BMI } \\
\text { and preoperative PSA level. On multivariate analysis, } \\
\text { controlling for the BMI, the preoperative PSA level } \\
\text { remained a significant predictor of the tumor volume. } \\
\text { The interaction between the preoperative PSA level and } \\
\text { BMI in the prediction of the tumor volume was not } \\
\text { statistically significant, suggesting that the BMI does not } \\
\text { affect the association between the PSA level and tumor } \\
\text { volume }\end{array}$ \\
\hline & & & \\
\hline
\end{tabular}

One study on 1,106 men undergoing radical prostatectomy between 1988 and 2002 showed the doubling in the percentage of obese men in the last 10 years. Obesity was associated with 
higher-grade tumors, a trend toward increased risk of positive surgical margins, and higher biochemical failure rates among men treated with radical prostatectomy. A BMI $\geq 35 \mathrm{~kg} / \mathrm{m}(2)$ was associated with a higher risk of failure than a BMI between 30 and $35 \mathrm{~kg} / \mathrm{m}(2)$ [14].

High BMI and prostate cancer recurrence and mortality: In their study on 2,131 patients undergoing radical prostatectomy Basset et al. [41] found that obesity (BMI > $35 \mathrm{mg} / \mathrm{kg} 2$ ) increased the risk of prostate cancer recurrence by comparison with moderately obese to nonobese men. However, after prostatectomy, BMI did not appear to be an independent predictor of recurrence or survival. Giovannucci et al. [42] reported the negative impact of adolescent obesity on overall health status.

Several studies conducted over the last decade have demonstrated the negative impact of obesity on cancer recurrence and mortality. Calle et al, [43] reported a 20-30\% higher risk of dying from prostate cancer in men who were overweight or obese or who had raised PSA at diagnosis and biochemical failure. Strom et al [44] found that the risk of such biochemical recurrence was higher among obese patients with prostate cancer. Using a community and academic based registry of 2,131 patients who underwent radical prostatectomy, Amling et al. [45] reported obesity as being associated with higher grade tumors and higher rates of disease recurrence after treatment

Kopp et al. [11] examined preoperative BMI and whole prostate weight in a cohort of 16,325 patients undergoing radical prostatectomy for localized prostate cancer from 1975 to 2008 at a single institution. In this US study, the authors demonstrated that preoperative BMI was associated with increased prostate weight. Compared to men with BMI $<25 \mathrm{~kg} / \mathrm{m}(2)$, those with a $\mathrm{BMI} \geq 35 \mathrm{~kg} / \mathrm{m}(2)$ were at a $40 \%$ higher risk of their prostate weighing over $40 \mathrm{~g}$ (odds ratio $1.40,95 \% \mathrm{CI} 1.01-1.95$ ) and a $70 \%$ higher risk of it being over $50 \mathrm{~g}$ (odds ratio $1.70,95 \%$ CI 1.32-2.20).

Obesity: modifiable risk factor of prostate cancer: As demonstrated above, many studies have shown that obesity is a risk factor for aggressive prostate cancer. Measures do however exist to reduce BMI, in contrast with other and non-modifiable risk factors of prostate cancer. Mounting evidence that reducing BMI may improve parameters influencing prostate cancer is positive. Reduced caloric intake leading to significant weight loss increases SHBG levels regardless of diet composition [46]. A review by Raben and Richelsen [47] showed that the use of artificial sweeteners to replace sugar, especially in beverages, can be a useful aid to maintain reduced energy intake and body weight and decrease the risk of type-2 diabetes and cardiovascular disease. The authors concluded that dietary effects on circulating SHBG, and possibly also on androgens, can be expected if body weight or fatness and/or insulin homeostasis are modulated.

Additionally, bariatric surgery can positively influence biological alterations affecting obese men with prostate cancer. In an observational study of morbidly obese males undergoing bariatric surgery, Pellitero et al [48] demonstrated that the obesity-associated hypogonadism highly prevalent in such a population is mostly reversed after sustained weight loss following surgery. 
Dietary patterns and management of obesity and prostate cancer using functional or medical foods and bioactive compounds

Dietary, functional foods and prostate cancer: There is strong evidence of the beneficial effects of functional foods for the treatment of obesity. However, the use of functional foods in prostate cancer is still premature for lack of large epidemiological studies [50]. Currently, solid evidence exists regarding diet and prostate cancer particularly when patients achieving healthful body weight through regular exercise and consuming a healthful plant-based regime rich in fruits, vegetables and complete grains. We have few studies focusing specifically in use of functional foods or supplements for cancer control. In fact, numerous studies with poor evidence-based medicine have been conducted on prostate cancer control and functional foods (e.g., soy and flaxseed), vitamins (e.g., vitamins D and E), micro-nutriments (e.g., selenium) and other food-related constituents (e.g., lycopene) [51].

Vitamin D has been presented to reduce cellular proliferation, increase apoptosis and inhibit invasion, migration, metastasis and angiogenesis [52,53]. The potential role of vitamin D in prostate tumor growth and aggressiveness is supported by environmental and case-control studies demonstrating an inverse relationship between prostate cancer mortality and advanced disease with ultraviolet (UV) exposure, which is the primary source of vitamin D [54-57]. Additionally, African Americans and older men who have reduced capacity for absorbing UV, presented an increased prostate cancer mortality [58-59]. Calcitriol, a vitamin D analog, had positive action as therapeutic agents for patients with castrate-resistant prostate cancer reduction in prostate-specific antigen levels and increasing patient survival, however the problem of avoiding hypercalcemia has not been overcome [60,61].

Primarily through the SELECT (Selenium and Vitamin E Cancer Prevention Trial) study, selenium and vitamin $\mathrm{E}$ have been shown to be beneficial for prostate cancer control. These supplements currently have no interest [62]. In addition, observational data from the Prostate, Lung, Colorectal, and Ovarian (PLCO) Cancer Screening Trial, which includes 29,361 men monitored for prostate cancer, indicate no relationship between the risk or progression of prostate cancer and dietary or supplemental intakes of vitamins $\mathrm{E}$ and $\mathrm{C}$ or beta-carotene [63]. Results of a RCT of 540 head and neck patients receiving radiotherapy and randomized to $400 \mathrm{IU} /$ day of vitamin $\mathrm{E}$ or placebo with 6.5-year median follow-up show significantly higher all-cause mortality in those taking vitamin $\mathrm{E}(\mathrm{HR}=1.38,95 \%$ CI 1.03-1.85), and increased cause-specific mortality [66].

Clark et al. reported findings of phase I-II trial that has analysed the impact of lycopene supplementation on biochemically-recurrent prostate cancer in 36 patients after definitive localized treatment [64]. Results of this small trial suggest that doses of lycopene from 15-90 mg per day were not associated with detectable changes in PSADT.

Chan et al. [65] have conducted a study on the impact of diet on risk of cancer progression in a cohort of 1,202 men diagnosed with incident localized/regional prostate cancer between 1986 and 1996. Men completed prospective dietary surveys before and after diagnosis and were followed through 2000. Authors examined post-diagnostic consumption of red meat, grains, vegetables, fruits, milk, tomatoes, tomato sauce, and fish as predictors of progression. In this study, they found significant protective associations for fish and tomato sauce, with Hazards Ratios $(\mathrm{HR})$ of $0.52(\mathrm{p}=0.006)$ and $0.46(\mathrm{p}=0.04)$ for each daily serving increase, respectively. 
Additionally, "moderate," but non-significant protective associations were found for vegetable consumption. In contrast, milk was found to increase risk for progressive disease $(\mathrm{HR}=1.12$; $\mathrm{p}=0.04$ for each daily serving). Interestingly and in contrast to tomato sauce, raw tomato consumption also was significantly associated with risk; a HR of $1.27(\mathrm{p}=0.02)$ was observed for each daily serving of raw tomatoes. While the inconsistency regarding tomato consumption is difficult to resolve, the authors attribute it partly to differences in lycopene absorption, since lycopene (a carotenoid previously associated with a protective effect for prostate cancer) is absorbed more readily from cooked, rather than raw tomatoes. These results also provide support that omega-3 fatty acid intakes may be protective, as well as vegetable consumption overall.

Obesity and functional foods: An increasing number of studies strongly support that obesityinduced inflammation plays an important role in the development of obesity-related pathologies. Nuclear factor kappa-light-chain-enhancer of activated $B$ cells (NF- $\kappa$ B) and c-Jun N-terminal kinases (JNK), the stress-activated protein kinase, are important modulators of inflammatory gene expression downstream of Toll-like receptor 4 (TLR4) in obese adipose tissues, which are regulated by peroxisome proliferator-activated receptor gamma (PPAR $\gamma$ ) [67]. In particular, PPAR $\gamma$ agonists can directly reduce adipocyte size and induce the expression of antiinflammatory cytokines, such as adiponectin [68]. Many foods components including Abietic acid (Pine rosin), Auraptene (Citrus Fruit), Capsaicin (Hot pepper), Dehydroabietic acid (Pine rosin), Isohumulone Humulus (lupulus hop), Isoprenoid (Herb), Resveratrol (Red wine) and 6Shogaol (Ginger) reduce obesity-induced inflammatory responses by suppressing the inflammatory signalling in a PPAR $\gamma$-dependent. Other dietary supplements act independently of PPARy but have an important anti-inflammatory role in the control of obesity and are represented by Anthocyanin (Red/PurplishFruit), Diosgenin Fenugreek (Yam), 6-Gingerol (Ginger) and Luteolin Herb (Spice) [67,68].

A recent review published by Choudhary $M$ and Grover K [69] confirmed the favourable role of functional foods in management of obesity. Authors proposed several nutrients basing on recent studies including low-glycemic-index carbohydrates, 5-hydroxytryptophan, green tea extract and chromium that have been shown to promote weight loss.

Conclusions: Obese patients have numerous biological alterations that provoke the aggressiveness of prostate cancer. However, obesity is a modifiable risk factor of prostate cancer.

Several studies have demonstrated the positive impact of nutrition on prostate cancer. But, the role of functional foods in the management of prostate cancer needs to be clarified through large epidemiological studies. Recent studies provide strong evidence of the positive role of regular activity, reduce caloric intake, functional foods and bariatric surgery for obesity-related pathologies control.

\section{$\underline{\text { List of abbreviations used }}$}

$\mathrm{BMI}=$ Body mass index

HDL $=$ High-density lipoprotein cholesterol

IGF-1= Insulin-growth factor-one 
IL-6= Interleukin 6

$\mathrm{JNK}=\mathrm{c}$-Jun N-terminal kinases/stress-activated protein kinase

PPARy $=$ peroxisome proliferator-activated receptor gamma

$\mathrm{PSA}=$ Prostate-specific antigen

$\mathrm{NF}-\kappa \mathrm{B}=$ nuclear factor kappa-light-chain-enhancer of activated $B$ cells

$\mathrm{SHBG}=$ Sex hormone binding globulin

TLR4= Toll-like receptor 4

$\mathrm{TNF}-\mathrm{a}=$ Tumor necrosis factor alpha

$\mathrm{WHO}=$ World Health Organization

WHR= Waist-to-hip

Competing interests: I (author) have no conflict of interests.

Author' contribution: I (author) conducted all work that led to the publication of this manuscript including Pubmed® and Embase $®$ research, writing, proofreading and corrections of the final version.

\section{Acknowledgements and Funding: None}

\section{REFERENCES:}

1. Jemal, A., et al., Cancer statistics, 2007. CA Cancer J Clin, 2007. 57(1): p. 43-66.

2. Boyle, P. and J. Ferlay, Cancer incidence and mortality in Europe, 2004. Ann Oncol, 2005. 16(3): p. 481-8.

3. Quinn, M. and P. Babb, Patterns and trends in prostate cancer incidence, survival, prevalence and mortality. Part II: individual countries. BJU Int, 2002. 90(2): p. 174-84.

4. Freedland, S.J., Obesity and prostate cancer: a growing problem. Clin Cancer Res, 2005. 11(19 Pt 1): p. 6763-6.

5. O'Malley, R.L. and S.S. Taneja, Obesity and prostate cancer. Can J Urol, 2006. 13 Suppl 2: p. 11-7.

6. van Leeuwen, P.J., et al., Prostate cancer mortality in screen and clinically detected prostate cancer: estimating the screening benefit. Eur J Cancer. 46(2): p. 377-83.

7. Cooperberg, M.R., J.M. Broering, and P.R. Carroll, Time trends and local variation in primary treatment of localized prostate cancer. J Clin Oncol. 28(7): p. 1117-23.

8. Hsing, A.W., L.C. Sakoda, and S. Chua, Jr., Obesity, metabolic syndrome, and prostate cancer. Am J Clin Nutr, 2007. 86(3): p. s843-57.

9. Freedland, S.J., J. Eastham, and N. Shore, Androgen deprivation therapy and estrogen deficiency induced adverse effects in the treatment of prostate cancer. Prostate Cancer Prostatic Dis, 2009. 12(4): p. 333-8.

10. Fowke, J.H., et al., Obesity, body composition, and prostate cancer. BMC Cancer. 12: p. 23.

11. Kopp, R.P., et al., Obesity and prostate enlargement in men with localized prostate cancer. BJU Int. 108(11): p. 1750-5. 
12. Xie, L.P., et al., Obesity and benign prostatic enlargement: a large observational study in China. Urology, 2007. 69(4): p. 680-4.

13. Freedland, S.J., et al., Obesity and biochemical outcome following radical prostatectomy for organ confined disease with negative surgical margins. J Urol, 2004. 172(2): p. 520-4.

14. Freedland, S.J., et al., Impact of obesity on biochemical control after radical prostatectomy for clinically localized prostate cancer: a report by the Shared Equal Access Regional Cancer Hospital database study group. J Clin Oncol, 2004. 22(3): p. 446-53.

15. Ploussard, G., et al., The risk of upstaged disease increases with body mass index in low-risk prostate cancer patients eligible for active surveillance. Eur Urol. 61(2): p. 356-62.

16. Discacciati, A., N. Orsini, and A. Wolk, Body mass index and incidence of localized and advanced prostate cancer--a dose-response meta-analysis of prospective studies. Ann Oncol. 23(7): p. 1665-71.

17. Pongchaiyakul, C., et al., Prediction of percentage body fat in rural thai population using simple anthropometric measurements. Obes Res, 2005. 13(4): p. 729-38.

18. Hsing, A.W., et al., Prostate cancer risk and serum levels of insulin and leptin: a populationbased study. J Natl Cancer Inst, 2001. 93(10): p. 783-9.

19. Tewari, R., et al., Diet, obesity, and prostate health: are we missing the link? J Androl. 33(5): p. 763-76.

20. Wang, Y., et al., Decreased growth of established human prostate LNCaP tumors in nude mice fed a low-fat diet. J Natl Cancer Inst, 1995. 87(19): p. 1456-62.

21. Brand, J.S., et al., Testosterone, sex hormone-binding globulin and the metabolic syndrome: a systematic review and meta-analysis of observational studies. Int J Epidemiol. 40(1): p. 189-207.

22. Faris, J.E. and M.R. Smith, Metabolic sequelae associated with androgen deprivation therapy for prostate cancer. Curr Opin Endocrinol Diabetes Obes. 17(3): p. 240-6.

23. Kaaks, R. and P. Stattin, Obesity, endogenous hormone metabolism, and prostate cancer risk: a conundrum of "highs" and "lows". Cancer Prev Res (Phila). 3(3): p. 259-62.

24. Laaksonen, D.E., et al., The metabolic syndrome and smoking in relation to hypogonadism in middle-aged men: a prospective cohort study. J Clin Endocrinol Metab, 2005. 90(2): p. 7129.

25. Grossmann, M. and G. Wittert, Androgens, diabetes and prostate cancer. Endocr Relat Cancer. 19(5): p. F47-62.

26. Corona, G., et al., Type 2 diabetes mellitus and testosterone: a meta-analysis study. Int $\mathbf{J}$ Androl. 34(6 Pt 1): p. 528-40.

27. Ding, E.L., et al., Sex hormone-binding globulin and risk of type 2 diabetes in women and men. N Engl J Med, 2009. 361(12): p. 1152-63.

28. Vikan, T., et al., Low testosterone and sex hormone-binding globulin levels and high estradiol levels are independent predictors of type 2 diabetes in men. Eur J Endocrinol. 162(4): p. 747-54.

29. Bosland, M.C., A perspective on the role of estrogen in hormone-induced prostate carcinogenesis. Cancer Lett.

30. Steppan, C.M., et al., The hormone resistin links obesity to diabetes. Nature, 2001. 409(6818): p. 307-12. 
31. Dandona, P., et al., Tumor necrosis factor-alpha in sera of obese patients: fall with weight loss. J Clin Endocrinol Metab, 1998. 83(8): p. 2907-10.

32. Hsing, A.W., et al., Body size and prostate cancer: a population-based case-control study in China. Cancer Epidemiol Biomarkers Prev, 2000. 9(12): p. 1335-41.

33. Hsing, A.W., et al., Insulin resistance and prostate cancer risk. J Natl Cancer Inst, 2003. 95(1): p. 67-71.

34. Giri, D., M. Ozen, and M. Ittmann, Interleukin-6 is an autocrine growth factor in human prostate cancer. Am J Pathol, 2001. 159(6): p. 2159-65.

35. Muller, H., et al., Association of diabetes and body mass index with levels of prostatespecific antigen: implications for correction of prostate-specific antigen cutoff values? Cancer Epidemiol Biomarkers Prev, 2009. 18(5): p. 1350-6.

36. Grubb, R.L., 3rd, et al., Serum prostate-specific antigen hemodilution among obese men undergoing screening in the Prostate, Lung, Colorectal, and Ovarian Cancer Screening Trial. Cancer Epidemiol Biomarkers Prev, 2009. 18(3): p. 748-51.

37. Mitchell, C.R., et al., Does body mass index "dilute" the predictive property of prostatespecific antigen for tumor volume at radical prostatectomy? Urology. 78(4): p. 868-72.

38. Goris Gbenou M.C., Peltier A., Lopez J.G. and van Velthoven R., The influence of increased $\mathrm{BMI}$ as risk factor of localized prostate cancer in patients undergoing radical prostatectomy [abstract]. J Urol, 2012. 187(4): p. A1-A56, 1521-1944

39. Rodriguez, C., et al., Body mass index, height, and prostate cancer mortality in two large cohorts of adult men in the United States. Cancer Epidemiol Biomarkers Prev, 2001. 10(4): p. 345-53.

40. Capitanio, U., et al., Influence of obesity on tumour volume in patients with prostate cancer. BJU Int. 109(5): p. 678-84.

41. Bassett, W.W., et al., Impact of obesity on prostate cancer recurrence after radical prostatectomy: data from CaPSURE. Urology, 2005. 66(5): p. 1060-5.

42. Giovannucci, E., et al., Height, body weight, and risk of prostate cancer. Cancer Epidemiol Biomarkers Prev, 1997. 6(8): p. 557-63.

43. Calle, E.E., et al., Overweight, obesity, and mortality from cancer in a prospectively studied cohort of U.S. adults. N Engl J Med, 2003. 348(17): p. 1625-38.

44. Strom, S.S., et al., Obesity, weight gain, and risk of biochemical failure among prostate cancer patients following prostatectomy. Clin Cancer Res, 2005. 11(19 Pt 1): p. 6889-94.

45. Amling, C.L., et al., Pathologic variables and recurrence rates as related to obesity and race in men with prostate cancer undergoing radical prostatectomy. J Clin Oncol, 2004. 22(3): p. 439-45.

46. Morisset, A.S., K. Blouin, and A. Tchernof, Impact of diet and adiposity on circulating levels of sex hormone-binding globulin and androgens. Nutr Rev, 2008. 66(9): p. 506-16.

47. Raben, A. and B. Richelsen, Artificial sweeteners: a place in the field of functional foods? Focus on obesity and related metabolic disorders. Curr Opin Clin Nutr Metab Care. 15(6): p. 597-604.

48. Pellitero, S., et al., Hypogonadotropic Hypogonadism in Morbidly Obese Males Is Reversed After Bariatric Surgery. Obes Surg. 
49. De Nunzio, C., et al., The uncertain relationship between obesity and prostate cancer: an Italian biopsy cohort analysis. Eur J Surg Oncol. 37(12): p. 1025-9.

50. Wendy Demark-Wahnefried. Dietary Intervention in the Management of Prostate Cancer. Curr Opin Urol. 2007;17(3): p.168-174.

51. Doyle C, Kushi LH, Byers T, et al. Nutrition and Physical Activity During and After Cancer Treatment: An American Cancer Society Guide for Informed Choices. CA Cancer J Clin 2006;56: p.323-353.

52. Holick MF. Vitamin D: its role in cancer prevention and treatment. Prog Biophys Mol Biol. 2006;92(1): p.49-59.

53. Krishnan AV, Peehl DM, Feldman D. Inhibition of prostate cancer growth by vitamin D: regulation of target gene expression. J Cell Biochem. 2003; 88(2): p.363-371.

54. Robsahm TE, Tretli S, Dahlback A, Moan J. Vitamin D3 from sunlight may improve the prognosis of breast- colon- and prostate cancer (Norway). Cancer Causes Control. 2004; 15(2):149-158.

55. John EM, Schwartz GG, Koo J, Van Den Berg D, Ingles SA. Sun exposure vitamin D receptor gene polymorphisms and risk of advanced prostate cancer. Cancer Res. 2005; 65:5470-5479. [PubMed:15958597]

56. Schwartz GG, Hanchette CL. UV Latitude and spatial trends in prostate cancer mortality: all sunlight is not the same (United States). Cancer Causes Control. 2006; 17(8):1091-1101.

57. Lagunova Z, Porojnicu AC, Dahlback A, Berg JP, Beer TM, Moan J. Prostate cancer survival is dependent on season of diagnosis. Prostate. 2007; 67(12):1362-1370.

1. 58. Johnson MA, Davey A, Park S, Hausman DB, Poon LW. Age race and season predict vitamin D status in African American and white octogenarians and centenarians. J Nutr Health Aging. 2008;12(10):690-695.

58. American Cancer Society. Cancer facts \& figures 2008. American Cancer Society; 2008. p. $1-68$.

59. Vijayakumar S, Mehta RR, Boerner PS, Packianathan S, Mehta RG. Clinical trials involving vitamin D nalogs in prostate cancer. Cancer J. 2005; 11(5):362-373.

60. Beer TM, Ryan CW, Venner PM, Petrylak DP, Chatta GS, Ruether JD, Redfern CH, Fehrenbacher L, Saleh MN, Waterhouse DM, Carducci MA, Vicario D, Dreicer R, Higano CS, Ahmann FR, Chi KN, Henner WD, Arroyo A, Clow FW. Double-blinded randomized study of high-dose calcitriol plus docetaxel compared with placebo plus docetaxel in androgen-independent prostate cancer: a report from the ASCENT Investigators. J Clin Oncol. 2007; 25(6):669-674.

61. Lippman SM, Goodman PJ, Klein EA, et al. Designing the Selenium and Vitamin E Cancer Prevention Trial (SELECT). J Natl Cancer Inst 2005;97:94-102.

62. Kirsh VA, Hayes RB, Mayne ST, et al. Supplemental and dietary vitamin E, beta carotene, and vitamin $\mathrm{C}$ intakes and prostate cancer risk. J Natl Cancer Inst 2006;98:245-254.

63. Clark PE, Hall MC, Borden LS Jr, et al. Phase I-II prospective dose-escalating trial of lycopene in patients with biochemical relapse of prostate cancer after definitive local therapy. Urology 2006;67:1257-1261. 
64. Chan JM, Holick CN, Leitzmann MF, et al. Diet after diagnosis and the risk of prostate cancer progression, recurrence, and death (United States). Cancer Causes Contr 2006; 17:199-208.

65. Bairati I, Meyer F, Jobin E, et al. Antioxidant vitamins supplementation and mortality: a randomized trial in head and neck cancer patients. Int J Cancer 2006;119:2221-2224.

66. Shizuka Hirai, Nobuyuki Takahashi, Tsuyoshi Goto, Shan Lin, Taku Uemura, Rina Yu, and Teruo Kawada. Functional Food Targeting the Regulation of Obesity-Induced Inflammatory Responses and Pathologies. Mediators of Inflammation Volume 2010, Article ID 367838, 8 pages doi:10.1155/2010/367838.

67. Yamauchi, J. Kamon, H. Waki, et al., "The mechanisms by which both heterozygous peroxisome proliferator-activated receptor $\gamma(\operatorname{PPAR} \gamma)$ deficiency and PPAR $\gamma$ agonist improve insulin resistance," The Journal of Biological Chemistry, vol. 276, no. 44, pp. 41245-41254, 2001.

68. Choudhary M, Grover K. Development of functional food products in relation to obesity. Functional Foods in Health and Disease 2012, 2(6):188- 197. 